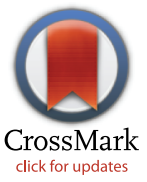

\section{G OPENACCESS}

Citation: Partridge CG, MacManes MD, Knapp R, Neff BD (2016) Brain Transcriptional Profiles of Male Alternative Reproductive Tactics and Females in Bluegill Sunfish. PLoS ONE 11(12): e0167509. doi:10.1371/journal.pone.0167509

Editor: Hanping Wang, Ohio State University, UNITED STATES

Received: May 5, 2016

Accepted: November 15, 2016

Published: December 1, 2016

Copyright: @ 2016 Partridge et al. This is an open access article distributed under the terms of the Creative Commons Attribution License, which permits unrestricted use, distribution, and reproduction in any medium, provided the original author and source are credited.

Data Availability Statement: The datasets supporting the conclusions of this article are available on the Sequence Read Archive (SRA) through BioProject ID: PRJNA287763.

Environmental data, RNA quality information, the assembled transcriptome, the transcript count matrix, and $R$ code for differential gene analysis are available on Dryad (doi: 10.5061/dryad.82fd8).

Funding: Funding for this project was supported through the Natural Sciences and Engineering Research Council of Canada (NSERC) to B.D.N (\#250071-2012) and the University of Oklahoma Department of Biology to R.K. The funders had no
RESEARCH ARTICLE

\section{Brain Transcriptional Profiles of Male Alternative Reproductive Tactics and Females in Bluegill Sunfish}

\author{
Charlyn G. Partridge ${ }^{1,2 *}$, Matthew D. MacManes ${ }^{3}$, Rosemary Knapp ${ }^{4}$, Bryan D. Neff ${ }^{2}$
}

1 Annis Water Resources Institute, Grand Valley State University, Muskegon, Michigan, United States of America, 2 Department of Biology, University of Western Ontario, London, Ontario, Canada, 3 Department of Molecular, Cellular, and Biomedical Sciences, University of New Hampshire, Durham, New Hampshire, United States of America, 4 Department of Biology, University of Oklahoma, Norman, Oklahoma, United States of America

* partridc@gvsu.edu

\section{Abstract}

Bluegill sunfish (Lepomis macrochirus) are one of the classic systems for studying male alternative reproductive tactics (ARTs) in teleost fishes. In this species, there are two distinct life histories: parental and cuckolder, encompassing three reproductive tactics, parental, satellite, and sneaker. The parental life history is fixed, whereas individuals who enter the cuckolder life history transition from sneaker to satellite tactic as they grow. For this study, we used RNAseq to characterize the brain transcriptome of the three male tactics and females during spawning to identify gene ontology $(\mathrm{GO})$ categories and potential candidate genes associated with each tactic. We found that sneaker males had higher levels of gene expression differentiation compared to the other two male tactics. Sneaker males also had higher expression in ionotropic glutamate receptor genes, specifically AMPA receptors, compared to other males, which may be important for increased spatial working memory while attempting to cuckold parental males at their nests. Larger differences in gene expression also occurred among male tactics than between males and females. We found significant expression differences in several candidate genes that were previously identified in other species with ARTs and suggest a previously undescribed role for cAMP-responsive element modulator $(\mathrm{crem})$ in influencing parental male behaviors during spawning.

\section{Introduction}

Understanding the molecular mechanisms that influence variation in behavior can provide insight into how different behavioral phenotypes within populations evolve and are maintained. One important area of research on behavioral phenotypes focuses on alternative reproductive tactics (ARTs), which are found in a wide array of taxa [1-5]. ARTs typically consist of larger males practicing a "territorial" tactic that maintain and protect breeding territories and smaller "sneaking" males that sneak fertilizations rather than compete with territorial males [6]. The mechanisms underlying the expression of ARTs can differ significantly across species. 
role in any study design, data collection and analysis, decision to publish, or preparation of the manuscript.

Competing Interests: The authors have declared that no competing interests exist.
In some cases, tactics are fixed for life (fixed tactics) [6] and can represent distinct life histories. Fixed tactics can occur through either inherited genetic polymorphisms [7-10], conditiondependent switches that are triggered prior to sexual maturation $[1,6,11]$, or a combination of genetic and environmental factors $[12,13]$. In other cases, individuals can exhibit different tactics throughout their reproductive life, either as they grow or in response to changing social or environmental context (plastic tactics or status-dependent tactics) [1,4,6,14]. Advances in sequencing technology, such as RNA sequencing (RNAseq), now allow behavioral ecologists to explore how variation in gene expression contributes to behavioral variation among mating tactics and examine if genes associated with these behaviors differ across species with ARTs.

Next-generation sequencing has led to more in-depth research into the molecular mechanisms driving ARTs [9,15-20]. For example, development of independent (territorial) males and two alternative tactics, satellite males and female-mimicking (faeder) males in a shorebird (the ruff, Philomachus pugnax) is driven by a supergene resulting from a chromosome inversion that contains 125 genes potentially influencing ART traits $[9,10]$. However, due to the lack of reference genomes for most teleosts, much of the work on ARTs in this group has focused on examining differential gene expression to identify genes associated with these tactics. These studies have found a large number of genes that vary among tactics in expression in the brain during mating. In the ocellated wrasse (Symphodus ocellatus), 1,048 genes were differentially expressed when comparing sneakers to two other male tactics (nesting and satellite) and to females [19]. In the black-faced blenny (Tripterygion delaisi) and peacock blenny (Salaria pavo), RNAseq identified approximately 600 transcripts differentially expressed within the brains of 'sneaker' versus other male tactics $[18,20]$. In another study, approximately 2,000 transcripts were differentially expressed between intermediate-sized sailfin molly (Poecilia latipinna) males performing courtship behaviors compared to small sneaker males [17].

With the increase in genomic studies examining differences among ARTs, there are a growing number of candidate genes associated with these tactics. Schunter et al. [18] proposed a list of potential candidate genes based on a number of studies (Table 1). Many of these genes are involved in hormone regulation and vertebrate mating behavior, and differences in expression levels have been observed among mating tactics in different fish species. For example, the product of the cyp19alb gene is aromatase B, the key enzyme responsible for the conversion of androgens to estrogens within the brain of vertebrates [e.g., 24,31]. Higher levels of cyp19a1b brain expression have been observed in territorial males compared to sneaker males in the peacock blenny [23], black-faced blenny [18], and an African cichlid (Astatotilapia burtoni) [16] but higher levels have been observed in sneaker male plainfin midshipman (Porichthys notatus) [25]. As more data become available, the number of candidate genes in this list will likely increase and evaluating gene expression across teleosts will aid in determining whether similar molecular pathways drive ART behaviors across different species.

One of the best-studied vertebrate species with male ARTs is the bluegill sunfish (Lepomis macrochirus). Male bluegill have two distinct life histories: parental and cuckolder. In Lake Opinicon (Ontario, Canada), all bluegill tactics spawn within large breeding colonies. Parental males are part of the parental life history and mature at around seven years of age (Fig 1). These males construct nests, court females, and provide care to young [32]. Males in the cuckolder life history become reproductively mature around two years of age [32]. Initially these males use a "sneaking" tactic (i.e., sneakers) to dart in and out of nests within the colony to cuckold fertilizations while parental males and females are spawning. As they grow, sneakers transition into a "satellite" tactic and take on female-like coloration and behaviors [32, 33]. Satellite males use this female mimicry to enter a parental male nest and cuckold fertilizations [34]. The parental and cuckolder life histories are fixed-once a male adopts the parental or cuckolder life history, he remains in that life history [35]. However, within the cuckolder life 
Table 1. Proposed candidate genes (from [18]) influencing teleost alternative reproductive tactics (ARTs). POA = Pre-optic area

\begin{tabular}{|c|c|c|}
\hline Proposed Candidate Genes & Function & Relationship to ARTs \\
\hline Arginine vasotocin (avt) & $\begin{array}{l}\text { Non-mammalian homolog of vasopressin. Activates some } \\
\text { aspects of sexual behavior }\end{array}$ & $\begin{array}{l}\uparrow \text { in posterior POA of territorial cichlid males, but } \uparrow \\
\text { anterior POA of non-territorial [21]; } \downarrow \text { density of avt mRNA } \\
\text { in POA in parental blenny males [22] }\end{array}$ \\
\hline $\begin{array}{l}\text { Gonadotropin releasing } \\
\text { hormone (gnrh) }\end{array}$ & $\begin{array}{l}\text { Regulates release of luteinizing hormone and follicle- } \\
\text { stimulating hormone from the pituitary gland }\end{array}$ & $\uparrow$ in territorial cichlid males [16] \\
\hline $\begin{array}{l}\text { Cytochrome P450 family } 19 \text {, } \\
\text { subfamily A, polypeptide } 1 \\
\text { (cyp19a1) }\end{array}$ & Brain aromatase. Key enzyme in estrogen biosynthesis & $\begin{array}{l}\uparrow \text { in territorial cichlid males [16]; } \uparrow \text { territorial blenny males } \\
{[23] ; \uparrow \text { territorial black-faced blenny males [18]; } \downarrow \text { in the }} \\
\text { sonic motor nucleus and ventromedial nucleus of nesting } \\
\text { type I (territorial) male plainfin midshipman compared to } \\
\text { type II (sneaker) males }[24,25]\end{array}$ \\
\hline Ependymin (epd) & $\begin{array}{l}\text { Glycoprotein associated with neuroplasticity and neuronal } \\
\text { regeneration. Also affects aggression levels in zebrafish [26]; } \\
\text { Associated with stress in trout [27] }\end{array}$ & $\begin{array}{l}\uparrow \text { in territorial cichlid males [16]; } \downarrow \text { in subordinate trout } \\
\text { males [26] }\end{array}$ \\
\hline $\begin{array}{l}\text { Galanin/GMAP prepropeptide } \\
\text { (gal) }\end{array}$ & $\begin{array}{l}\text { Neuropeptide that influences neurotransmitters. Associated } \\
\text { with male sexual behaviors [28] and parental care [29] }\end{array}$ & $\boldsymbol{\uparrow}$ in territorial cichlid males [16] \\
\hline Somatostatin (sst) & $\begin{array}{l}\text { Neuropeptide that regulates endocrine pathways. Also affects } \\
\text { neurotransmitters }\end{array}$ & $\begin{array}{l}\uparrow \text { in territorial blenny males [18]; } \uparrow \text { in territorial cichlid } \\
\text { males [16] }\end{array}$ \\
\hline $\begin{array}{l}\text { Early growth response } 1 \\
\text { (egr1) }\end{array}$ & Transcription factor that influences neural plasticity & $\begin{array}{l}\text { 个 when subdominant cichlid males switch to dominant } \\
\text { [30] }\end{array}$ \\
\hline
\end{tabular}

doi:10.1371/journal.pone.0167509.t001

history, mating tactics are developmentally plastic, with males apparently transitioning from the sneaker tactic to the satellite tactic as they age [35].

While the spawning behavior, reproductive success, and hormone profiles of bluegill have been studied extensively [35, 37-41], the genes influencing behavioral differences during spawning are less clear [42]. Thus, for this study, we used RNAseq to characterize the brain transcriptome of the three spawning male tactics (parental, sneaker, and satellite), non-spawning parental males, and spawning females to examine how differences in gene expression may relate to behavioral variation among these groups. Specifically, we aim to (1) assess whether or not there is a greater difference in gene expression profiles between tactics in different life histories (parental versus the two cuckolder tactics) than between tactics within the same life history (sneaker versus satellite), (2) identify specific gene ontology categories that are expressed for each tactic, (3), examine the expression of potential candidate genes identified from other fish species to determine if they also differentiate ARTs in bluegill, and (4) compare expression differences between male and female bluegill.

\section{Materials and Methods}

\section{Bluegill Sampling}

In June 2013, bluegill sunfish were collected via dip net from Lake Opinion near Queen's University Biological Station (QUBS), Elgin, Ontario, Canada. A total of 12 parental males, 12 sneaker males, 13 satellite males, and 12 females were collected on the same day directly from the bluegill colony while in the act of spawning. All spawning fish used in this study were behaviorally verified as to tactic by snorkelers prior to collection. An additional 12 non-nesting parental males were collected off of the colony four days prior to spawning (as determined once spawning at these colonies began) and were used as our non-spawning parental males. These males were reproductively mature but were in between spawning bouts. Individuals were euthanized using clove oil, total body length was measured, and whole brains were immediately dissected out and stored in RNAlater (Life Technologies, Carlsbad, CA). The total amount of time required for euthanasia, brain dissection, and brain storage in RNAlater was 


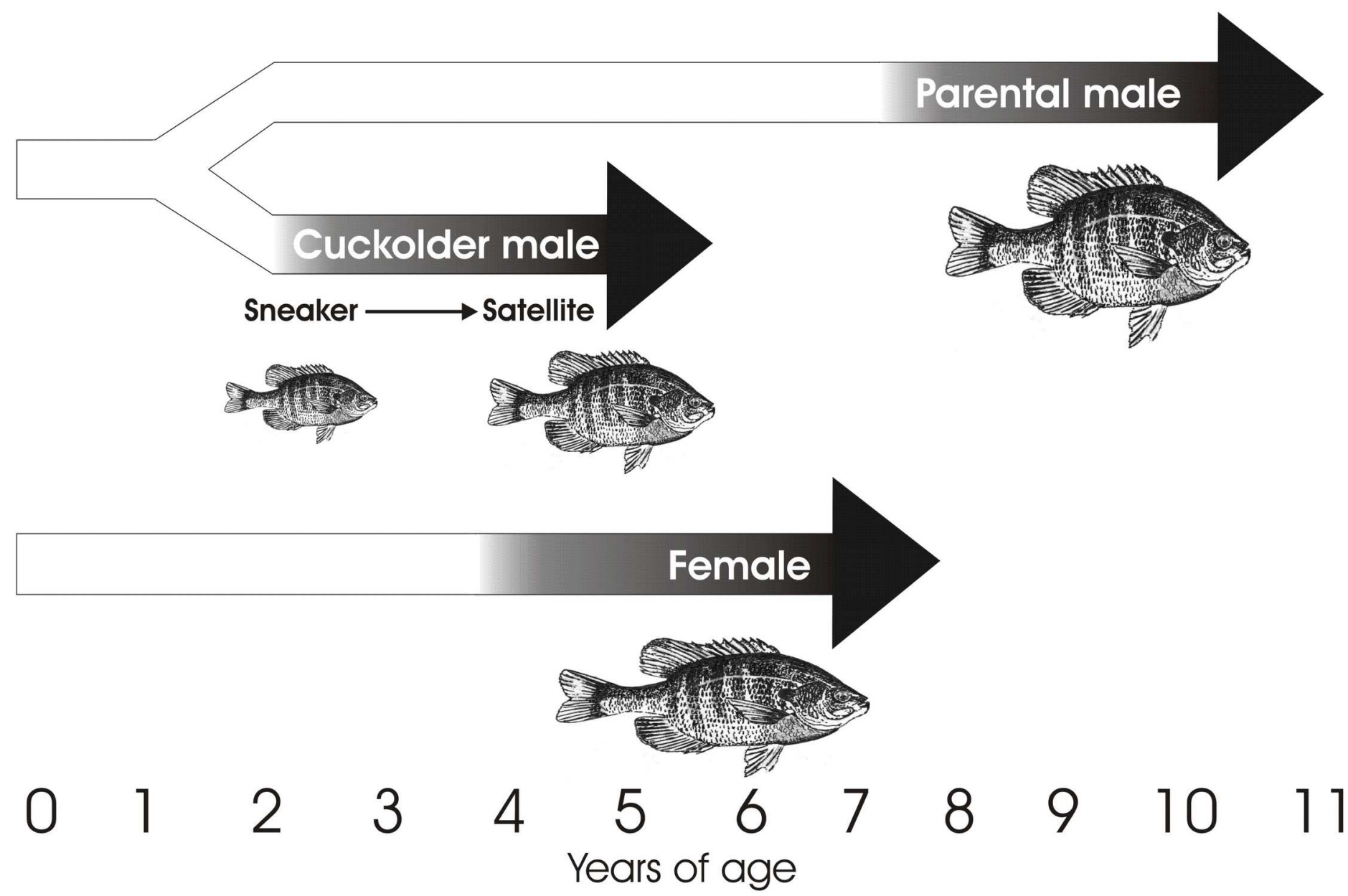

Fig 1. Alternative reproductive tactics of bluegill sunfish. This figure has been modified from Gross and Charnov [35] and Neff and Knapp [36]. Ages are based on data from Gross and Charnov [35] but may differ among populations [33].

doi:10.1371/journal.pone.0167509.g001

under 5 minutes. Brains remained in RNAlater at $4^{\circ} \mathrm{C}$ for 24 hours and were then transferred to fresh cryovials, flash frozen, and kept in liquid nitrogen until they were transported on dry ice to the University of Western Ontario. Samples were then stored at $-80^{\circ} \mathrm{C}$ until total RNA extraction. The Animal Care Committee at Western University (UCC) approved all procedures performed in this study (AUP \# 2010-214).

\section{Total RNA Extraction}

Total RNA was extracted from whole brains using a standard Trizol (Life Technologies, Carlsbad, CA) extraction protocol (https://tools.thermofisher.com/content/sfs/manuals/trizol reagent.pdf). Total RNA was submitted to the London Genomics Center at the University of Western Ontario and quality was assessed using a 2100 Bioanalyzer (Agilent Technologies, Palo Alto, CA). Four individuals from each group (spawning parental males, non-spawning parental males, sneaker males, satellite males, and females), for a total of 20 individuals, were submitted to the Michigan State University Research Technology Support Facility-Genomics Center for cDNA library construction and sequencing. Individuals used for this study had RIN (RNA Integrity Number) values ranging from 9.2-9.9. 


\section{cDNA Library Construction and Sequencing}

The cDNA libraries were constructed for each individual using Illumina TrueSeq Stranded mRNA Library Preparation Kits LT (Illumina, San Diego, CA), with each individual receiving a uniquely identifiable index tag. The quality of each library was evaluated and the 20 individuals were multiplexed into a single sample that was subsequently run on two lanes of an Illumina HiSeq2500 Rapid Run flow cell (v1). Sequencing was performed on paired end 2 x 150 bp format reads and bases were called using Illumina Real Time Analysis software (v1.17.21.3). Reads from each individual were identified based on their unique index tag, separated, and converted to fastq files using Illumina Bcl2fastq v1.8.4. Sequencing produced an average of 14.5 million reads per individual, with over $90 \%$ of the reads having a Q-score $>30$.

\section{De novo Transcriptome Assembly and Reference Transcriptome}

Prior to assembly, read quality was assessed using FastQC (http://www.bioinformatics.

babraham.ac.uk/projects/fastqc). Nucleotides whose quality score was below PHRED $=2$ were trimmed using Trimmomatic version 0.32 [43], following recommendations from MacManes [44]. The reference transcriptome was assembled de novo using Trinity version 2.04 [45,46]. One representative of each of the five groups (spawning parental male, non-spawning parental male, sneaker male, satellite male, and female) was used to construct a combined reference transcriptome. The five representatives selected for the reference were the individuals with the highest number of reads within their group and a total of 85 million paired-end reads were assembled. The assembly was normalized using Trinity's (version 2.04) in silico normalization program. The fully assembled transcriptome consisted of 235,547 transcripts. To determine whether this was an appropriate representation of the bluegill brain transcriptome, reads from samples not used in the assembly were mapped back to the transcriptome using BurrowsWheeler Aligner (bwa)-mem version 0.7.12 [47], and $>90 \%$ of those reads aligned, which is comparable to the rate of mapping for the individuals used in the assembly (92\%).

TransDecoder [45] was used to identify protein-coding regions within the assembled transcriptome. Transcripts were blasted using Blastn to a custom database containing complete coding sequences (cds) and non-coding RNA (ncRNA) from spotted green puffer (Tetraodon nigroviridis), spotted gar (Lepisosteus oculatus), southern platyfish (Xiphophorus maculatus), medaka (Oryzias latipes), Japanese pufferfish (Takifugu rubripes), West Indian Ocean coelacanth (Latimeria chalumnae), Mexican tetra (Astyanax mexicanus), zebrafish (Danio rerio), and Amazon molly (Poecilia formosa) (downloaded from Ensembl). Transcripts that contained protein coding regions or those that blasted to the customized fish database with an e-value less that $1 \times 10^{-3}$ comprised the reference transcriptome and this was used for read alignment and to estimate transcript counts. This reference consisted of 72,189 transcripts, including isoforms, with a mean transcript length of 2,024 bp, a N50 =3,106 bp and a N90 = 1,018 bp.

\section{Read Alignment and Transcript Counts}

Reads from each individual were separately aligned to the reference transcriptome using bwamem 0.7.10 [47]. At least $85 \%$ of all reads from each individual mapped back to the reference, with the majority aligning $90 \%$ of reads or higher. The sequence alignment/map (sam) files were then converted to a binary format (bam) using Samtools 0.1.19 [48]. Transcript counts for each individual were obtained using the program eXpress 1.5.1 [49]. Unless otherwise indicated, all programs were run using the default options. Differential gene expression was determined using the R statistical package edgeR 3.6.8 [50]. Transcripts with cpm values of $<10$ for at least 4 individuals were filtered out prior to analysis, leaving 19,084 transcripts. While this filtering process is conservative, we are less likely to observe false positives due to outliers with 
highly variable expression, which is common for transcripts with low counts. Transcript counts were normalized to account for differences in cDNA library size among individuals and dispersion parameters were estimated using Tagwise dispersion estimates. Differences in gene expression between groups were calculated using an Exact-test for binomial distribution. Genes with p-values lower than 0.05 after false discovery rate (FDR) correction were determined to be statistically significant. All fold changes are reported as $\log 2$ fold change. Hierarchical cluster analysis to visualize overall group differences was performed on only those transcripts with FDR values below 0.05 and with $\log 2$ fold changes greater than 1.5 (equaling 1,400 transcripts) using the R package ggplot2 (2.1.0) [51].

\section{Gene Annotation and Enrichment Analysis}

For gene annotation, all transcripts were blasted using the program Blastx against a customassembled fish protein database. This database consisted of Ensembl protein databases of 13 different fish species: Amazon molly (Poecilia formosa), zebrafish (Danio rerio), Mexican tetra (Astyanax mexicanus), Atlantic cod (Gadus morhua), West Indian Ocean coelancanth (Latimeria chalumnae), Japanese pufferfish (Takifugu rubripes), sea lamprey (Petromyzon marinus), medaka (Oryzias latipes), southern platyfish (Xiphophorus maculatus), spotted gar (Lepisosteus oculatus), three-spined stickleback (Gasterosteus aculeatus), green spotted pufferfish (Tetradon nigroviridis), and Nile tilapia (Oreochromis niloticus). Blast hits with e-values less than $1 \times 10^{-10}$ were considered significant. All annotated transcripts used for differential expression analysis are listed in S1 Table. Ensembl IDs from the blast hits were then converted into GO term identifiers using Biology Database Network (bioDBnet) (http://biodbnet.abcc.ncifcrf.gov/db/ dbFind.php).

For the transcripts that were differentially expressed among behavioral groups, enrichment analysis was conducted using a Fisher Exact test in the R Stats package (v 3.3.1) to examine whether the proportion of genes within each GO category was significantly higher than expected based upon the proportion of expressed genes assigned to that GO term within the reference transcriptome. To ensure adequate statistical power, only GO terms with at least 10 transcripts within each category were included in the statistical analysis. A FDR correction was applied to control for multiple testing and GO terms with p-values $<0.05$ were considered to be significant. Visual representations of enriched GO terms were generated using REVIGO [52].

\section{Results}

\section{Differential Gene Expression across All Groups}

Hierarchical cluster analysis of the top differentially expressed transcripts showed sneaker males grouped separately from the other male tactics (Fig 2). Satellite males tended to have expression profiles intermediate between sneakers and the other groups.

When comparing across all groups, five transcripts consistently displayed higher expression in spawning parental males compared to all other groups (Table 2). Fourteen transcripts were differentially expressed in satellite males compared to all other groups. Expression for these transcripts in satellite males was higher compared to parental males (spawning and nonspawning) and females, but lower compared to sneaker males (Table 2). There were 2,253 transcripts differentially expressed between sneaker males and all other groups (S2 Table). The majority of these transcripts with higher expression in sneakers were related to ion transport, ionotropic glutamate signaling pathway, and mRNA processing (Fig 3). Two transcripts were differentially expressed in females compared to the other groups and both of these were expressed at lower levels than in the other groups (Table 2). 


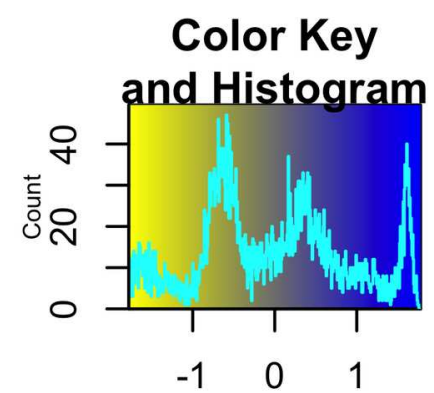

Row Z-Score

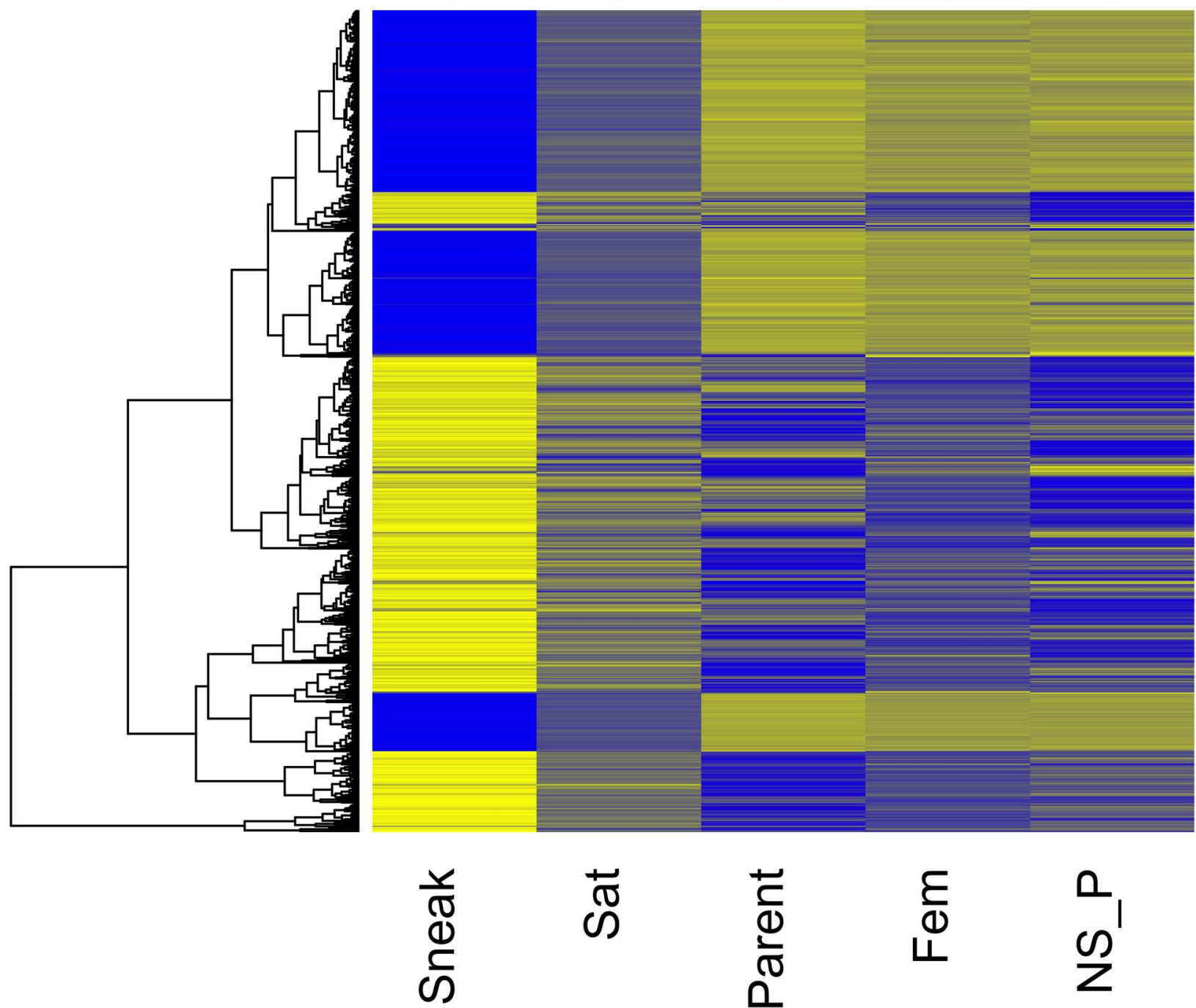

Fig 2. Heatmap of transcripts differentially expressed in at least one group comparison. Only transcripts with a log2 fold change of 1.5 or greater are included in the heatmap, representing 1,400 transcripts. Count values were averaged within each group and are scaled by row. Sneak $=$ sneaker males, Sat $=$ satellite males, Parent $=$ parental males, Fem $=$ females, NS_P = non-spawning parental males.

doi:10.1371/journal.pone.0167509.g002 
Table 2. Differentially expressed transcripts associated with each male mating tactic and females.

\begin{tabular}{|c|c|}
\hline Sunfish Focal Group & Differentially Expressed Genes \\
\hline $\begin{array}{l}\text { Parental Males (Spawning)_Expression levels } \\
\text { are higher in parental males compared to other } \\
\text { groups, except for MHC class } 1 \text { antigen. }\end{array}$ & $\begin{array}{l}- \text { Pancreatic progenitor cell differentiation and } \\
\text { proliferation (ppdpf): } \mathrm{FC}=1.8 \\
\text { - Potassium voltage-gated channel, Isk-related family, } \\
\text { member } 4 \text { ( } k c n e 4) \text { : } \mathrm{FC}=1.4 \\
\text { - Cysteine dioxygenase type } 1 \text { (cdo1), } 3 \text { isoforms: } \\
\mathrm{FC}=1.7 \\
-\mathrm{cAMP}-\text { responsive element modulator }(\mathrm{crem}), 2 \\
\text { isoforms: } \mathrm{FC}=2.1 \\
- \text { MHC class } 1 \text { antigen: } \mathrm{FC}=-5.5\end{array}$ \\
\hline $\begin{array}{l}\text { Satellite Males-Fold changes are higher } \\
\text { compared to parental males (spawning and non- } \\
\text { spawning) and females but lower compared to } \\
\text { sneaker males. }\end{array}$ & 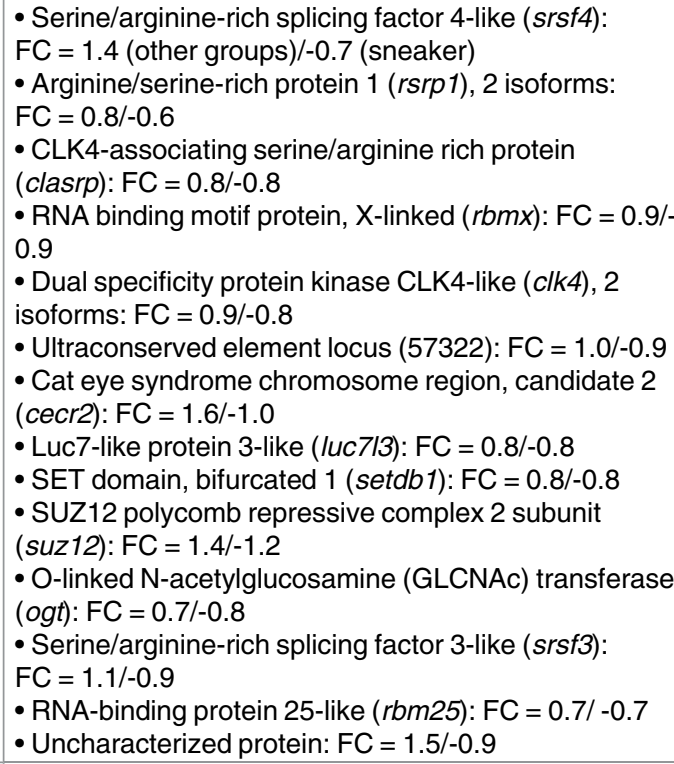 \\
\hline Sneaker Males- & $\begin{array}{l}\text {-2,253 differentially expressed transcripts (S2 Table) } \\
\text { - Transcripts with high expression related to ion } \\
\text { transport, ionotropic glutamate receptor signaling } \\
\text { pathway, and mRNA processing (Fig 3) }\end{array}$ \\
\hline $\begin{array}{l}\text { Females-Expression levels are lower compared } \\
\text { to other groups }\end{array}$ & $\begin{array}{l}\text { - Protachykinin-like (tac): FC = }-1.6 \\
\text { - Galanin/GMAP prepropeptide (gal): FC = -1.7 }\end{array}$ \\
\hline
\end{tabular}

$\mathrm{FC}=$ Mean log2 fold change across comparisons. Positive numbers indicate expression levels that were higher in focal group compared to other groups, negative numbers indicate expression is lower in focal group. For satellite males, the first FC value is the mean log2 fold change of satellite males compared to spawning, non-spawning parental males, and females. The second FC value is satellite males compared to sneaker males. When transcripts had multiple isoforms, FC values were averaged across isoforms.

doi:10.1371/journal.pone.0167509.t002

\section{Between Life History Comparisons}

Spawning Parental Males versus Sneaker Males. A total of 9,279 transcripts were differentially expressed between spawning parental males and sneaker males (Fig 4). Of these, 4,537 transcripts showed higher expression in parental males ( $\mathrm{S} 3$ Table) and 4,742 transcripts showed higher expression in sneaker males (S4 Table).

Enrichment analysis of GO terms associated with differentially expressed genes showed that the biological functions most enriched in parental males included translation initiation, translation elongation, proteolysis involved in cellular protein catabolism, and oxidationreduction processes ( 55 Table). The 27 molecular processes most enriched in parental males 


\title{
regulation of ion transmembrane
} transport

\author{
ionotropic \\ glutamate receptor \\ signaling pathway
}

calcium

ion

transmembrane transport

mRNA

processing potassium

ion

transmembrane

transport

protein

transport

Fig 3. Biological process GO terms enriched by genes with higher expression in sneaker males compared to all other groups. Boxes of similar color are grouped into the same GO term hierarchy. Box size reflects the-log10 p-value of the GO term.

doi:10.1371/journal.pone.0167509.g003

compared to sneaker males included ribosomal structure, oxidoreductase activity and catalytic activity (S5 Table).

Biological processes enriched with genes displaying higher expression in sneaker males included ion transport, homophilic cell adhesion, protein phosphorylation, ionotropic glutamate receptor signaling pathway, and synaptic transmission ( 55 Table). The 10 molecular processes enriched in sneaker males included ion channel activity, protein binding, and ionotropic glutamate receptor activity (S5 Table).

Spawning Parental Males versus Satellite Males. A total of 1,141 transcripts were differentially expressed between spawning parental males and satellite males (Fig 4). Of these, 676 transcripts had higher expression in parental males (S6 Table) and 465 transcripts showed higher expression in satellite males (S7 Table).

One GO term related to biological function, oxidation-reduction processes, was enriched in parental males compared to satellite males (S5 Table). Six GO terms related to molecular processes were enriched in parental males ( 55 Table). These were iron ion binding, two types of oxidoreductase activity, heme binding, acylCoA dehydrogenase activity and catalytic activity (S5 Table).

Only one GO term related to biological function, ion transport, was enriched in satellite males compared to spawning parental males ( 55 Table). Three GO terms related to molecular processes were enriched in satellite males relative to spawning parental males. These were nucleic acid binding, ion channel activity, and GTP binding (S5 Table). 


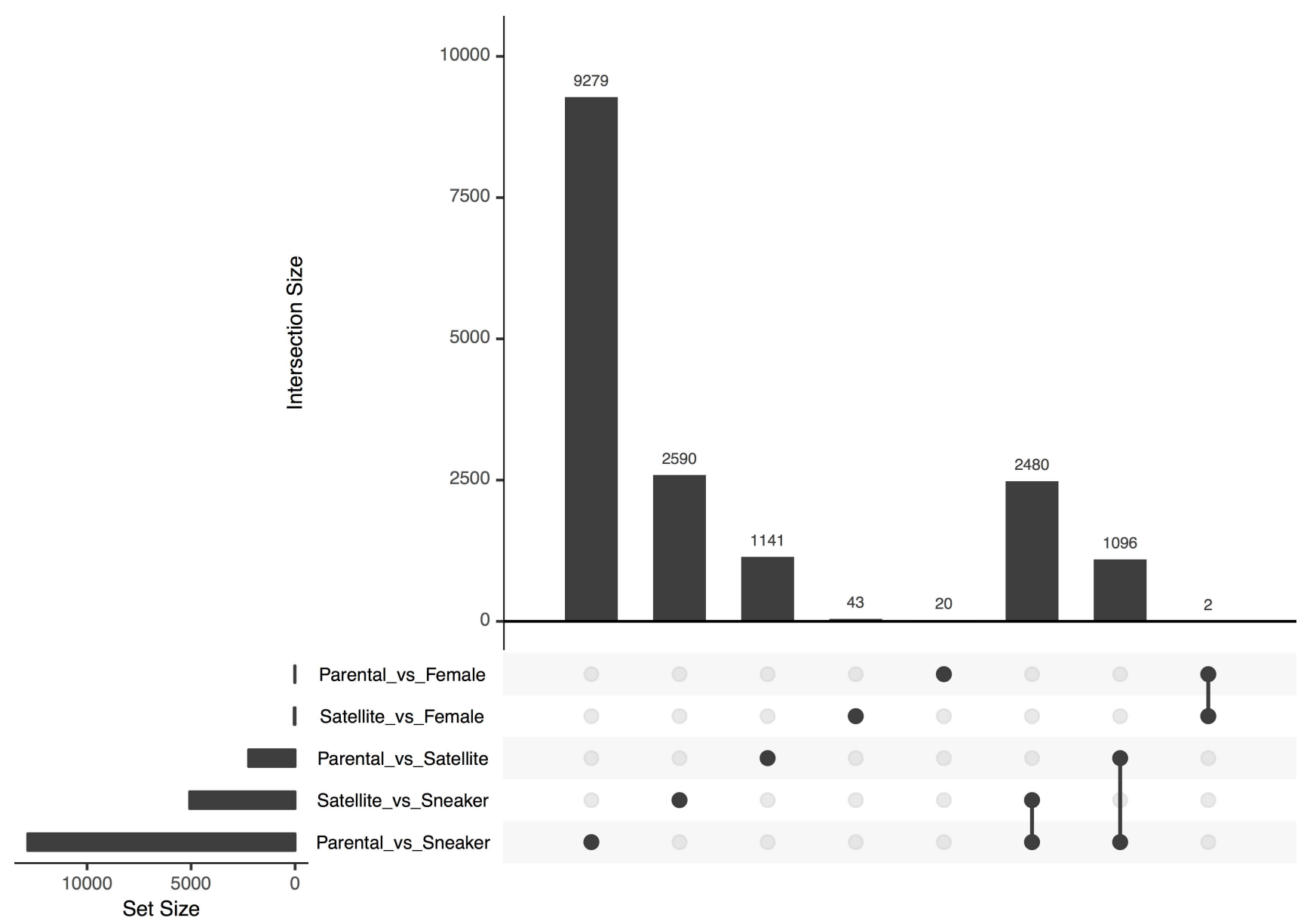

Fig 4. UpSet graph displaying the number of differentially expressed transcripts among groups. For each comparison, the number on top of each bar represents the number of differentially expressed transcripts (intersection size). The comparison in question is indicated by the dots or connected dots below its respective bar. Set size indicates the total number of transcripts for each comparison.

doi:10.1371/journal.pone.0167509.g004

\section{Differential Expression within Life Histories}

Satellite Males verses Sneaker Males. There were 2,590 transcripts differentially expressed between satellite males and sneaker males (Fig 4). Of these, 2,480 transcripts were also differentially expressed between spawning parental and sneaker males (Fig 4) and all showed expression to be in the same direction for parental and satellite males compared to sneakers (i.e. those with higher expression in parental males compared to sneaker males were also higher in satellite males compared to sneakers). Only 110 transcripts were differentially expressed in satellite males compared to sneaker males that were not also differentially expressed between parental and sneaker males. Seventy-six transcripts had higher expression levels in satellite males (S8 Table) and 34 transcripts had higher expression in sneaker males (S9 Table). The number of transcripts differentially expressed was too low to have adequate statistical power to perform enrichment analysis for GO terms. However, many of the transcripts with higher expression in satellite males are associated with GTP catabolism, while transcripts with higher expression in sneaker males are involved in signal transduction, neural crest cell migration, and DNA integration.

Spawning Parental Males verses Non-Spawning Parental Males. A total of 137 transcripts were differentially expressed between spawning and non-spawning parental males. The 
majority of these transcripts (132 transcripts) showed higher expression in spawning males (S10 Table). Genes with the highest expression in spawning parental males compared to nonspawning males were MHC II beta antigen, cytosolic 5'-nucleotidase II ( $n t 5 c 2$ ), cAMP responsive element modulator a ( $\mathrm{crem}$ ), cysteine dioxygenase type 1 ( $c d o 1)$, and an uncharacterized protein. Only 8 transcripts showed higher expression in non-spawning parental males. These were nuclear receptor subfamily 1 group $\mathrm{D}$ member $4 \mathrm{~b}(n r 1 d 4 b)$, neuronal tyrosine-phosphoinositide-3-kinase adaptor 2 (nyap2), sphingosine-1-phosphate receptor 4 (s1pr4), gamma-aminobutyric acid A receptor beta 3 ( $g a b r b 3$ ), and four uncharacterized proteins (S11 Table).

Again, the number of transcripts assigned to GO terms was too small to have adequate statistical power to perform an enrichment analysis for this comparison.

\section{Potential Candidate Genes Associated with ART Spawning Behavior}

We observed differential expression of a number of transcripts previously identified as candidate genes associated with differences in ART behaviors (described in Table 1) (Table 3). In our data set, the candidate genes cyp19a1b, epd, and gal showed higher expression in spawning parental males compared to sneaker males. Epd also had higher expression in satellite males compared to sneakers. Egrl showed higher expression in both satellite and sneaker males relative to spawning parental males. Sst1 showed higher expression in satellite males compared to sneaker males, but no differences in other comparisons between tactics. No differences in expression related to gnrh, avt, or sst 3 were observed between any of our groups.

Another transcript that displayed large differences in expression between spawning parental males and all other groups (including non-spawning males) was cAMP-responsive element modulator (crem) (Table 2). Multiple isoforms of the transcript were expressed, with log2 fold changes ranging from 1.3-2.6 times higher in spawning parental males compared to other groups. Consistent with the findings for GO term enrichment, transcripts that showed the highest levels of expression in sneaker males compared to other groups were related to glutamate receptor genes, particularly AMPA ionotropic glutamate receptors (S2 Table).

In addition to the candidate genes listed in Table 1, a number of endocrine genes were differentially expressed among two or more male tactics. Among these are a number of genes that we consider bluegill candidate genes based on documented male tactic differences in circulating steroid hormone levels on the day of spawning [37,38,41]. Some of these include oxytocin, pro-melanin concentrating hormone-like, prostaglandin, and corticotropin releasing hormone receptor 2 (S2 Table, S3 Table). Further investigation of these specific hormone-associated genes is currently in progress and will be reported elsewhere.

Table 3. Gene expression differences (log2 fold change) among male tactics for proposed candidate genes (see Table 1).

\begin{tabular}{l|c|c|c|c|c}
\hline & & \multicolumn{4}{|c}{ Comparison between Male Tactics (Log2 Fold Change) } \\
\hline Proposed Candidate Gene & Isoform ID & Parent vs Sneak & Parent vs Sat & Sat vs Sneak & Spawn Parent vs NonSpawn \\
\hline Arginine vasotocin (avt) & c34708_g2_i1 & $0.45(0.32)$ & $-0.98(0.09)$ & $0.54(0.33)$ & $0.74(0.50)$ \\
\hline Gonadotropin releasing hormone $(g n r h)$ & c63124_g1_i1 & $0.76(0.50)$ & $0.32(0.87)$ & $0.44(0.77)$ & $0.77(0.88)$ \\
\hline Cytochrome P450 19a1b (cyp19a1b) & c48084_g2_i1 & $\mathbf{0 . 9 3 ( 0 . 0 0 0 2 )}$ & $0.64(0.06)$ & $0.28(0.40)$ & $0.39(0.58)$ \\
\hline Ependymin (epd) & c44195_g1_i5 & $\mathbf{1 . 5 4 ( 1 . 4 \times 1 0 - 8 )}$ & $0.66(0.07)$ & $\mathbf{0 . 8 9 ( 0 . 0 0 7 )}$ & $-0.51(0.45)$ \\
\hline Galanin/GMAP prepropeptide (gal) & c41071_g5_i2 & $\mathbf{1 . 1 2 ( 0 . 0 0 0 1 )}$ & $0.53(0.91)$ & $-0.59(0.10)$ & $0.09(0.97)$ \\
\hline Somatostatin 1 (sst1) & c30013_g1_i1 & $0.53(0.15)$ & $-0.39(0.49)$ & $\mathbf{0 . 9 3 ( 0 . 0 3 )}$ & $0.27(0.88)$ \\
\hline Somatostatin 3 (sst3) & c46547_g6_i1 & $0.001(1.00)$ & $-0.25(0.54)$ & $0.25(0.48)$ & $0.15(0.90)$ \\
\hline Early growth response 1 (egr1) & c37907_g1_i1 & $\mathbf{- 0 . 7 4 ( 0 . 0 2 )}$ & $\mathbf{- 0 . 9 1 ( 0 . 0 3 )}$ & $0.16(0.72)$ & \\
\hline
\end{tabular}

Values in brackets represent $p$-values after false discovery rate correction. Values in bold are significant at $p<0.05$. Parent $=$ parental male, Sneak $=$ sneaker male, Sat $=$ satellite male, NonSpawn $=$ non-spawning parental male .

doi:10.1371/journal.pone.0167509.t003 


\section{Sex Differences}

Two transcripts were differentially expressed between females and all of the male groups (sneaker, satellite, spawning parental male, and non-spawning parental male) (Table 2). These corresponded to galanin/GMAP prepropeptide $(\mathrm{gal})$ and protachykinin $(\mathrm{tac})$ and both were expressed at lower levels in females. The number of differentially expressed genes between females and satellite males was higher than between females and parental males (Fig 4), despite females and satellites exhibiting some similarity in spawning behavior. The relatively low number of differentially expressed genes observed between males and females may be due to higher variation in gene expression among females compared to males (S1 Fig).

The datasets supporting the conclusions of this article are available on the Sequence Read Archive (SRA) through BioProject ID: PRJNA287763. Environmental data, RNA quality information, the assembled transcriptome, the transcript count matrix, and $\mathrm{R}$ code for differential gene analysis are available on Dryad (doi: 10.5061/dryad.82fd8).

\section{Discussion}

Bluegill sunfish are a classic system for examining behavioral differences in ARTs. In this study, we generated and assembled the first bluegill brain transcriptome and identified candidate genes associated with different male spawning tactics. The main differences in gene expression were found between sneaker males when compared to the two other male tactics and females. Generally, sneaker males showed higher expression in transcripts influencing neural activity, whereas parental and satellite males exhibited higher expression in genes related to translation and oxidoreductase activity. There were larger differences in transcript expression among different male tactics than between males and females.

\section{Overall Expression Differences among ARTs}

One of our main findings is that shared life history is not a driving factor influencing similarity in brain gene expression among tactics. In bluegill, parental and cuckolder life histories are fixed, but within the cuckolder life history, males transition from the sneaking to the satellite tactic as they age $[32,35]$. Our data showed that, regardless of whether comparisons were made across fixed (parental versus sneaker or parental versus satellite) or plastic (sneaker versus satellite) tactics, sneaker males showed the highest level of differentiation in gene expression. The expression differences in sneakers may be partially due to age and size considering sneaker males are both younger and smaller than satellite and parental males. Genes associated with increased age in other fish species, such as translation elongation and ribosomal proteins [53], had higher levels of expression in parental and satellite males compared to sneaker males in our dataset. However, age and size are not likely the only factors contributing to these differences. The differences in expression observed in this study are also likely to be reflective of behavioral differences exhibited by these tactics. For example, sneaker males in Atlantic salmon, Salmo salar, show higher expression of genes related to neural activity [15] compared to immature males of similar age and size. While we were not able to separate the effects of age, size, or behavioral tactic for our data, many of the genes with higher expression in bluegill sneakers are related to similar gene pathways (synaptic transmission) that were observed in the Atlantic salmon study. Thus, while age and size are likely responsible for some of these expression differences, they are also a reflection of different behavioral tactics and not just exclusively the result of different life histories. 


\section{Gene Categories Associated with ARTs}

Identifying distinct gene categories expressed by ART types provides information regarding which functional gene categories may be associated with behavioral differences during spawning. As mentioned above, previous studies in Atlantic salmon and sailfin mollies, Poecilia latipinna, indicate that sneaker males have increased expression of genes related to neurotransmission and learning [15,17]. We found that the GO terms enriched in bluegill sneaker males compared to all other groups were the ionotropic glutamate signaling pathway and ionotropic glutamate receptor activity. Ionotropic glutamate receptors are primarily excitatory neurotransmitter receptors and play an important role in fast synaptic transmission (reviewed in [54]). Two of these receptors, NMDA and AMPA, play important roles in memory function and spatial learning (reviewed in [55]). Blocking NMDA receptors impairs learning new spatial locations in goldfish [56] and mice with impaired AMPA receptors show normal spatial learning but have impaired spatial working memory (i.e. their ability to alter their spatial choice in response to changing environments is impaired) [57]. We propose that increased expression of genes related to spatial memory, particularly spatial working memory, could be important for bluegill sneakers during spawning as they attempt to enter nests while avoiding detection by parental males and common predators around the colony [58]. Bluegill sneakers must also position themselves in close proximity to females to time sperm release to coincide with female egg release [59]. Similarly, sailfin molly sneakers, who also show enrichment in ionotropic glutamate related genes [17], probably benefit from increased spatial working memory as they position themselves by the female for quick and successful copulations. In this context, increased expression in gene pathways that improve neural function related to spatial working memory would be especially beneficial for sneaking tactics to increase their reproductive success.

While ARTs with fixed tactics maintain the same mating tactic over their lifetime, ARTs with plastic tactics can alter their behavior and, in some cases, their phenotype when switching from one tactic to another. Different phenotypes can be accomplished without altering the underlying genomic sequence through a number of mechanisms including epigenetic regulation, alternative gene splicing, and post-translational modification of proteins [60,61]. A number of genes involved in these processes showed higher expression in the plastic tactics (satellite and sneaker) compared to the fixed parental tactic (Table 2). For example, ogt plays a key role in chromatin restructuring and post-translational modification of proteins [62]. It has been also implicated in a number of different processes including nutrient and insulin signaling [63,64], sex-specific prenatal stress [65], and behavioral plasticity [66]. Genes associated with alternative splicing that were expressed at higher levels in plastic tactics included isoforms of serine/arginine-rich proteins (SR proteins), a family of proteins involved in RNA splicing [67], and CLK-4 like proteins, which are kinases that function in regulating SR protein activity [68]. Similarly, differential expression of RNA splicing genes has also been observed in two other teleost species with plastic tactics, the black-faced blenny and intermediate-sized sailfin mollies $[17,18]$. While the mechanisms influencing how ART males switch between tactics is currently unresolved, epigenetic regulation, alternative gene splicing, and post-transcriptional modifications could be important for plastic tactics in altering their phenotype in response to environmental or developmental cues.

\section{Candidate Genes Associated with ARTs}

A number of candidate genes have been proposed to influence the expression of ARTs in teleosts [18] (Table 1). In our study of bluegill, we corroborate some of these candidates. Similar to many other species, cyp19a1b, epd, and gal had higher expression levels in spawning 
parental males compared to sneaker males. Expression levels of cyp19a1b (brain aromatase) on the day of spawning initially seem contrary to what would be expected based on observed differences in circulating androgen and estrogen levels in male bluegill morphs. Estradiol (E2) and testosterone (T) levels have been shown to increase cyp19a1b expression in a number of teleosts [69,70], however 11-ketotestosterone (11-KT) shows little to no effect [70]. In bluegill, sneaker males have higher circulating levels of $\mathrm{E} 2$ and $\mathrm{T}$ compared to parental males on the day of spawning, while 11-KT levels are higher in parental males during this time [41]. However, testosterone levels of parental males can peak just prior to or on the day spawning [37,71] possibly influencing the higher expression in cyp19a1b we observed.

The one candidate gene that was expressed opposite to expectations was egrl. Egr1 expression was lower in bluegill spawning parental males compared to sneaker or satellite males although previous work in cichlids found that expression of this gene increases when subdominant males transition into dominant males [30]. Egr1 is an important transcription factor involved in neural plasticity [72], so it may be one of a group of genes involved in regulating the switch from one tactic to another. Taken together, our results corroborate roles for cyp19a1b, epd, gal, and egrl as candidate genes contributing to behavioral differences in ARTs across multiple species. Future work will explore how candidate genes are expressed across different brain regions, as some studies have found regional differences associated with genes, such as avt, in other species with ARTs [21, 73-76].

We also identified one transcript with a previously unrecognized function in influencing male spawning behavior for any teleost. Transcripts corresponding to isoforms of $\mathrm{crem}$ were expressed at significantly higher levels in spawning parental males compared to all other male groups, including non-spawning parental males. Crem plays a key role in modulating the hypothalamic-pituitary-gonadal (HPG) axis by regulating transcriptional responses to cAMP in neuroendocrine cells and also serves as an important activator of spermatogenesis in Sertoli cells of mice [77-79]. This gene can act as both transcriptional activator and inhibitor depending on the splice variant produced [77]. One splice variant is inducible cAMP early repressor (ICER), a powerful repressor of cAMP-regulated transcription [80]. ICER plays a key role in circadian melatonin synthesis by repressing the key enzyme that converts serotonin to melatonin [81]. High levels of these neurotransmitters have been associated with increased mating and cooperative behavior and decreased aggressive behavior [82-84]. ICER has not yet been well characterized in teleosts but one of our differentially expressed crem transcripts had a significant blast hit to an ICER variant from Epinephelus brunes (longtooth grouper). The relationship among crem, melatonin, and aggression is opposite to what would be expected if ICER is playing a role since parental males have darker pigmentation and are more aggressive than other groups [58, 8587]. However, increased expression of $\mathrm{crem}$, whether through ICER or another crem transcript variant, could be a candidate gene influencing behaviors associated with parental male spawning given its role in transcriptional regulation and its involvement in the HPG axis.

\section{Sex Differences}

Neural differences between the sexes are common and found in many taxa (reviewed in $[88,89])$. However, within ARTs, differences in neural expression profiles can often be larger among male tactics than between males and females [18-20]. In bluegill, only two transcripts were consistently differentially expressed in females when compared to all male groups and these corresponded to $g a l$ and tac. Gal and tac are neuropeptides and neurons expressing these genes have been associated with male sexual behavior and aggression $[28,90]$. Injections of gal into the preoptic area (MPOA) of the brain increase sexual behaviors in male rats [28] and stimulate both male-typical and female-typical sexual behaviors in females [91]. In male rats, 
testosterone can enhance the pituitary's response to galanin (endoded for by gal), which heightens gonadotropin releasing hormone's $(\mathrm{GnRH})$ stimulation of luteinizing hormone. If gal is directly involved in regulating gnrh expression in bluegill, this neuropeptide may play an important role in behavioral differences between the sexes. In sequential hermaphroditic fish, surges in GnRH drive the switch from female to male [92]. Although bluegill are gonochoristic, gonadal sex is not evident until 30-60 days post hatch [93] and changes in sex can be hormonally induced [94]. Thus, gal expression, through its influence on gnrh expression, may play an important role in sex differences for this species.

The role of tac in influencing sexual behaviors in teleosts has not been addressed, but tac expression significantly increases in the brain of male eels (Anguilla anguilla) during sexual maturation [95] and leads to increased male aggression in Drosophila [90]. In bluegill, the primary role of tac expression may not be male-male aggression, considering higher expression levels of this gene are also observed in the non-aggressive satellite and sneaker males when compared to females. Although the ways in which gal and tac expression specifically influence sex-specific behaviors in bluegill is currently undefined, the fact that lower expression is consistently observed in females compared to all male groups suggests that these are important sex-specific neural genes.

In summary, our work describes differences in gene expression profiles in the brains of bluegill sunfish during spawning. The largest differences in expression levels were observed when comparing sneakers to parental males, satellite males, and females, suggesting that differences in gene expression are more related to male reproductive tactic than to life history. Consistent with other studies, our work demonstrates that sneaker males have greater expression of genes involved in neural function relative to more territorial-type males, particularly in relation to spatial working memory, as mediated by ionotropic glutamate receptors. We also found support for the previously identified candidate genes cyp19a1b, epd, gal, and egrl contributing to behavioral differences in ARTs and identified a potential new candidate gene, crem, for regulating parental males' behavior during spawning.

\section{Supporting Information}

S1 Fig. Multi-dimensional space (MDS) plot based on the biological coefficient of variation (bcv) among bluegill male ARTs and females.

S1 Table. Annotated transcripts used for differential gene expression. (TXT)

S2 Table. Transcripts differentially expressed in sneaker males compared to all other groups.

S3 Table. Transcripts with significantly higher expression in bluegill parental males compared to sneaker males.

(TXT)

S4 Table. Transcripts with significantly higher expression in bluegill sneaker males compared to parental males.

S5 Table. Biological process and molecular function GO terms that are significantly enriched with genes differentially expressed between tactics.

(XLSX) 
S6 Table. Transcripts with significantly higher expression in bluegill parental males compared to satellite males.

(TXT)

S7 Table. Transcripts with significantly higher expression in bluegill satellite males compared to parental males.

(TXT)

S8 Table. Transcripts with significantly higher expression in bluegill satellite males compared to sneaker males.

(TXT)

S9 Table. Transcripts with significantly higher expression in bluegill sneaker males compared to satellite males.

S10 Table. Transcripts with significantly higher expression in spawning parental males compared to non-spawning parental males.

(TXT)

S11 Table. Transcripts with significantly higher expression in non-spawning parental males compared to spawning parental males.

(TXT)

\section{Acknowledgments}

We thank Scott Colborne for his help in collecting bluegill, Dave Bridges for providing the $\mathrm{R}$ script to convert Ensemble IDs to stickleback homologs, and David Winter and Jeramia Ory for providing Python script used in the bioinformatics analyses. We thank Doug Haywick for producing Fig 1. We also thank Shawn Garner, Tim Hain, Lauren Kordonowy, and Lindsay Havens, and three anonymous reviewers for helpful comments on the manuscript.

\section{Author Contributions}

Conceptualization: CGP BDN RK.

Data curation: CGP.

Formal analysis: CGP MDM.

Funding acquisition: BDN RK.

Investigation: CGP MDM.

Methodology: CGP RK BDN.

Project administration: $\mathrm{CP} B D N$.

Visualization: CGP MDM.

Writing - original draft: CGP.

Writing - review \& editing: CGP MDM RK BDN.

\section{References}

1. Gross MR. Alternative reproductive strategies and tactics: diversity within sexes. Trends Ecol Evol. 1996; 11:92-8. PMID: 21237769 
2. Mank JE, Avise JC. The evolution of reproductive and genomic diversity in ray-finned fishes: insights from phylogeny and comparative analysis. J Fish Biol. 2006; 69:1-27.

3. Oliveira RF. Neuroendocrine mechanisms of alternative reproductive tactics in fish. In: Sloman KA, Wilson RW, Balshine S, editors. Behavior and Physiology of Fish. Fish Physiology. 2006; 24: 297-357.

4. Taborsky M, Oliveira RF, Brockmann HJ. The evolution of alternative reproductive tactics: concepts and questions. In: Oliveira RF, Taborksy M, Brockmann HJ, editors. Alternative reproductive tactics: an integrative approach. Cambridge: Cambridge University Press; 2008. p. 1-21.

5. Taborsky M, Brockmann HJ. Alternative reproductive tactics and life history phenotypes. In: Kappeler P, editor. Animal behavior: evolution and mechanisms. Berlin: Springer; 2010. p. 537-586.

6. Taborsky M. Sperm competition in fish: 'Bourgeois' males and parasitic spawning. Trends Ecol Evol. 1998; 13:222-7. PMID: 21238275

7. Lank DB, Smith CM, Hanotte O, Burke T, Cooke F. Genetic polymorphism for alternative mating behaviour in lekking male ruff Philomachus pugnax. Nature. 1995; 378:59-62.

8. Schuster SM, Sassaman C. Genetic interaction between male mating strategy and sex ratio in a marine isopod. Nature. 1997; 388:373-7.

9. Küpper C, Stocks M, Risse JE, dos Remedios N, Farrell LL, McRae SB, Morgan TC, Karlionova N, Pinchuk P, Verkuil YI, Kitaysky AS, Wingfield JC, Piersma T, Zeng K, Slate J, Blaxter M, Lank DB, Burke T. A supergene determines highly divergent male reproductive morphs in the ruff. Nature Genet. 2016; 48:79-83. doi: 10.1038/ng.3443 PMID: 26569125

10. Lamichhaney S, Fan G, Widemo F, Gunnarsson U, Schwochow Thalmann D, Hoeppner MP, Kerje S, Gustafson U, Shi C, Zhang H, Chen W, Liang X, Huang L, Wang J, Liang E, Wu Q, Lee SM-Y, Xu X, Höglund J, Liu X, Andersson L. Structural genomic changes underlie alternative reproductive strategies in the ruff (Philomachus pugnax). Nature Genet. 2016; 48:84-88. doi: 10.1038/ng.3430 PMID: 26569123

11. Gross MR, Repka J. Stability with inheritance in the conditional strategy. J Theor Biol. 1998; 192:445453. doi: 10.1006/jtbi.1998.0665 PMID: 9782102

12. Piché J, Hutchings JA, Blanchard W. Genetic variation in threshold reaction norms for alternative reproductive tactics in Atlantic salmon, Salmo salar. P Roy Soc Lond B Biol Sci. 2008; 275:1571-1575.

13. Neff BD, Svensson El. Polyandry and alternative mating tactics. Phil Trans R Soc B Biol Sci. 2013; 368:20120045.

14. Moore MC. Application of organization-activation theory to alternative male reproductive strategies: A review. Horm Behav. 1991; 25:154-179. PMID: 2066078

15. Aubin-Horth N, Landry CR, Letcher $\mathrm{BH}$, Hofmann HA. Alternative life histories shape brain gene expression profiles in males of the same population. P Roy Soc Lond B Biol Sci. 2005; 272:1655-1662.

16. Renn SC, Aubin-Horth N, Hofmann HA. Fish and chips: functional genomics of social plasticity in an African cichlid fish. J Exp Biol. 2008; 211:3041-3056. doi: 10.1242/jeb.018242 PMID: 18775941

17. Fraser BA, Janowitz I, Thairu M, Travis J, Hughes KA. Phenotypic and genomic plasticity of alternative male reproductive tactics in sailfin mollies. P Roy Soc Lond B Biol Sci. 2014; 281:20132310.

18. Schunter C, Vollmer SV, Macpherson E, Pascual M. Transcriptome analysis and differential gene expression in a non-model fish species with alternative mating tactics. BMC Genomics. 2014; 15:167. doi: 10.1186/1471-2164-15-167 PMID: 24581002

19. Stiver KA, Harris RM, Townsend JP, Hofmann HA, Alonzo SH. Neural gene expression profiles and androgen levels underlie alternative reproductive tactics in the ocellated wrasse, Symphodus ocellatus. Ethology. 2015; 121:152-167.

20. Cardoso SD, Gonçalves D, Goesmann A, Canário AVM, Oliveria RF. Brain transcriptome analysis of alternative reproductive tactics in a blenniid fish. The $35^{\text {th }}$ Annual Meeting of the J.B. Johnston Club for Evolutionary Neuroscience and the $27^{\text {th }}$ Annual Karger Workshop in Evolutionary Neuroscience. Brain Behav Evol. 2015; 85: 287-293.

21. Greenwood AK, Wark AR, Fernald RD, Hofmann HA. Expression of arginine vasotocin in distinct preoptic regions is associated with dominant and subordinate behaviour in an African cichlid fish. P Roy Soc Lond B Biol Sci. 2008; 275:2393-2402.

22. Grober MS, George AA, Watkins KK, Carneiro LA, Oliveira RF. Forebrain AVT and courtship in fish with male alternative reproductive tactics. Brain Res Bull. 2002; 57:423-425. PMID: 11923002

23. Gonçalves D, Teles M, Alpedrinha J, Oliveira RF. Brain and gonadal aromatase activity and steroid hormone levels in female and polymorphic males of the peacock blenny Salaria pavo. Horm Behav. 2008; 54:717-725. doi: 10.1016/j.yhbeh.2008.07.014 PMID: 18760279

24. Forlano $\mathrm{PM}, \mathrm{Bass} \mathrm{AH}$. Seasonal plasticity of brain aromatase mRNA expression in glia: divergence across sex and vocal phenotypes. Neurobiology. 2005; 65:37-49. 
25. Fergus DJ, Bass AH. Localization and divergent profiles of estrogen receptors and aromatase in the vocal and auditory networks of a fish with alternative mating tactics. J Comp Neurol. 2013; 521:2850 2869. doi: 10.1002/cne.23320 PMID: 23460422

26. Sneddon LU, Schmidt R, Fang Y, Cossins AR. Molecular correlates of social dominance: A novel role for ependymin in aggression. PLoS One. 2011; 6:e18181. doi: 10.1371/journal.pone.0018181 PMID: 21483679

27. Thomson JS, Watts PC, Pottinger TG, Sneddon LU. Physiological and genetic correlates of boldness: Characterizing the mechanisms of behavioral variation in rainbow trout, Oncorhynchus mykiss. Horm Behav. 2011; 59:67-74. doi: 10.1016/j.yhbeh.2010.10.010 PMID: 20965192

28. Bloch GJ, Butler PC, Kohlert JG, Bloch DA. Microinjection of galanin into the medial preoptic nucleus facilitates copulatory behavior in the male rat. Physiol Behav. 1993; 54:615-624. PMID: 7504308

29. Wu Z, Autry AE, Bergan JF, Watabe-Uchida M, Dulac CG. Galanin neurons in the medial preoptic area govern parental behavior. Nature. 2014; 509: 325-330. doi: 10.1038/nature13307 PMID: 24828191

30. Burmeister SS, Jarvis ED, Fernald RD. Rapid behavioral and genomic responses to social opportunity. PLOS Biol. 2005;e363. doi: 10.1371/journal.pbio.0030363 PMID: 16216088

31. Le Page $Y$, Diotel N, Vaillant $C$, Pellegrini E, Anglade I, Mérot $Y$, Kah O. Aromatase, brain sexualization and plasticity: the fish paradigm. Eur J Neurosci. 2010; 32:2105-2115. doi: 10.1111/j.1460-9568.2010. 07519.x PMID: 21143665

32. Gross MR. Sneakers, satellites and parentals: Polymorphic mating strategies in North American sunfishes. Z Tierpsychol. 1982; 60:1-26.

33. Dominey WJ. Female mimicry in male bluegill sunfish-a genetic polymorphism? Nature. 1980; 284:546-548.

34. Neff BD, Gross MR. Dynamic adjustment of parental care in response to perceived paternity. P Roy Soc Lond B Biol Sci. 2001; 268:1559-1565.

35. Gross MR, Charnov EL. Alternative male life histories in bluegill sunfish. Proc Nat Acad Sci USA. 1980; 77:6937-6940. PMID: 16592922

36. Neff BD, Knapp R. Alternative reproductive tactics in the Centrachidae. In: Cook SJ, Philipp DP, editors. Centrarchid Fishes: Diversity, Biology, and Conservation. West Sussex: John Wiles \& Sons Ltd; 2009. pp. 96.

37. Kindler PM, Philipp DP, Gross MR, Bahr JM. Serum 11-ketotestosterone and testosterone concentrations associated with reproduction in male bluegill (Lepomis macrochirus: Centrarchidae). Gen Comp Endocrinol. 1989; 75:446-453. PMID: 2792730

38. Kindler PM, Bahr JM, Philipp DP. The effects of exogenous 11-ketotestosterone, testosterone, and cyproterone acetate on prespawning and parental care behaviors of male bluegill. Horm Behav. 1991; 25:410-423. PMID: 1834540

39. Neff BD. Genetic paternity analysis and breeding success in bluegill sunfish (Lepomis macrochirus). J Hered. 2001; 92:111-119. PMID: 11396568

40. Neff BD. Increased performance of offspring sired by parasitic males in bluegill sunfish. Behav Ecol. 2004; 15:327-331.

41. Knapp R, Neff BD. Steroid hormones in bluegill, a species with male alternative reproductive tactics including female mimicry. Biol Lett. 2007; 3:628-631. doi: 10.1098/rsbl.2007.0379 PMID: 17911051

42. Partridge $\mathrm{C}$, Rodgers $\mathrm{CMC}$, Knapp R, Neff $\mathrm{BD}$. Androgen effects on immune gene expression during parental care in bluegill sunfish (Lepomis macrochirus). Can J Zool. 2015; 93:9-13.

43. Bolger AM, Lohse M, Usadel B. Trimmomatic: A flexible trimmer for Illumina sequence data. Bioinformatics. 2014;btf170.

44. MacManes MD. On the optimal trimming of high-throughput mRNA sequence data. Front Genet. 2014; 5:13. doi: 10.3389/fgene.2014.00013 PMID: 24567737

45. Haas BJ, Papanicolaou A, Yassour M, Grabherr M, Blood PD, Bowden J, Couger MB, MacManes MD, Ott M, Orvis J, Pochet N, Strozzi F, Weeks N, Westerman R, William T, Dewey CN, Henschel R, LeDuc RD, Friedman N, Regev A. De novo transcript sequence reconstruction from RNA-Seq using the Trinity platform for reference generation and analysis. Nature Protocols. 2013; 8:1494-1512. doi: 10.1038/ nprot.2013.084 PMID: 23845962

46. Grabherr MG, Haas BJ, Yassour M, Levin JZ, Thompson DA, Amit I, Adiconis X, Fan L, Raychowdhury R, Zeng Q, Chen Z, Mauceli E, Hacohen N, Gnirke A, Rhind N, di Palma F, Birren BW, Nusbaum C, Lindblad-Toh K, Friedman N, Regev A. Full-length transcriptome assembly from RNA-Seq data without a reference genome. Nature Biotechnol. 2011; 29:644-652.

47. Li H. Aligning sequence reads, clone sequences and assembly contigs with BWA-MEM 2013; arXiv:1303.3997v2 [q-bio.GN] 
48. Li H, Handsaker B, Wysoker A, Fennell T, Ruan J, Homer N, Marth G, Abecasis G, Durbin R, 1000 Genome Project Data Processing Subgroup. The sequence alignment/map (SAM) format and SAMtools. Bioinformatics. 2009; 25:2078-2079. doi: 10.1093/bioinformatics/btp352 PMID: 19505943

49. Roberts $A$, Pachter L. Streaming fragment assignment for real-time analysis of sequencing experiments. Nature Methods. 2013; 10:1-47.

50. Robinson MD, McCarthy DJ, Smyth GK. EdgeR: a Bioconductor package for differential expression analysis of digital gene expression data. Bioinformatics. 2010; 26:139-140. doi: 10.1093/ bioinformatics/btp616 PMID: 19910308

51. Wickham H. ggplot2: Elegant Graphics for Data Analysis. New York: Springer-Verlag; 2009.

52. Supek F, Bošnjak M, Škunca N, Šmuc T. REVIGO summarizes and visualizes long lists of Gene Ontology terms. PLOS ONE. 2011;

53. Baumgart M, Groth M, Priebe S, Savino A, Testa G, Dix A, Ripa R, Spallotta F, Gaetano C, Ori M, Tozzini ET, Guthke R, Platzer M, Cellerino A. RNA-seq of the aging brain in the short-lived fish N. furzericonserved pathways and novel genes associated with neurogenesis. Aging Cell. 2014; 13:965-974. doi: 10.1111/acel.12257 PMID: 25059688

54. Lamprecht R, LeDoux J. Structural plasticity and memory. Nature Rev Neurosci. 2004; 5:45-54.

55. Riedel G, Platt B, Micheau J. Glutamate receptor function in learning and memory. Behav Brain Res. 2003; 140:1-47. PMID: 12644276

56. Gómez Y, Vargas JP, Portavella M, López JC. Spatial learning and goldfish telencephalon NMDA receptors. Neurobiol Learn Mem. 2006; 85:252-262. doi: 10.1016/j.nlm.2005.11.006 PMID: 16464619

57. Reisel D, Bannerman DM, Schmitt WB, Deacon RMJ, Flit J, Borchardt T, Seeburg PH, Rawlins JNP. Spatial memory dissociations in mice lacking GluR1. Nature Neurosci. 2002; 5:868-873. doi: 10.1038/ nn910 PMID: 12195431

58. Gross MR, MacMillian AM. Predation and the evolution of colonial nesting in bluegill sunfish (Lepomis macrochirus). Behav Ecol Sociobiol. 1981; 8:163-174.

59. Stoltz JA, Neff BD. Male size and mating tactic influence proximity to females during sperm competition in bluegill sunfish. Behav Ecol Sociobiol. 2006; 59:811-818.

60. Aubin-Horth N, Renn SC. Genomic reaction norms: using integrative biology to understand molecular mechanisms of phenotypic plasticity. Mol Ecol. 2009; 18: 3763-3780. doi: 10.1111/j.1365-294X.2009. 04313.x PMID: 19732339

61. Marden JH. Quantitative and evolutionary biology of alternative splicing: how changing the mix of alternative transcripts affects phenotypic plasticity and reaction norms. Heredity. 2008; 100:111-120. doi: 10.1038/sj.hdy.6800904 PMID: 17006532

62. Myers SA, Panning B, Burlingame AL. Polycomb repressive complex 2 is necessary for the normal sitespecific O-GlcNAc distribution in mouse embryonic stem cells. Proc Natl Acad Sci USA. 2011; 201; 108:9490-9495. doi: 10.1073/pnas.1019289108 PMID: 21606357

63. Yang X, Ongusaha PP, Miles PD, Havstad JC, Zhang F, So WV, Kudlow JE, Michell RH, Olefsky JM, Field SJ, Evans RM. Phosphoinositide signalling links O-GlcNAc transferase to insulin resistance. Nature. 2008; 451:964-969. doi: 10.1038/nature06668 PMID: 18288188

64. Lagerlöf O, Slocomb JE, Hong I, Aponte Y, Blackshaw S, Hart GW, Huganir RL. The nutrient sensor OGT in PVN neurons regulates feeding. Science. 2016; 341: 1293-1296.

65. Howerton CL, Morgan CP, Fischer DB, Bale TL. O-GlcNAc transferase (OGT) as a placental biomarker of maternal stress and reprogramming of CNS gene transcription in development. Proc Natl Acad Sci USA. 2013; 110:5169-5174. doi: 10.1073/pnas.1300065110 PMID: 23487789

66. Rexach JE, Clark PM, Mason DE, Neve RL, Peters EC, Hsieh-Wilson LC. Dynamic O-GlcNAc modification regulates CREB-mediated gene expression and memory formation. Nature Chem Biol. 2012; 8:253-261.

67. Bourgeois CF, Lejeune F, Stévenin. Broad specificity of SR (Serine/Arginine) proteins in the regulation of alternative splicing of pre-messenger RNA. Prog Nucl Acid Res. 2004; 78:37-88.

68. Stamm S. Regulation of alternative splicing by reversible protein phosphorylation. J Biol Chem. 2008; 283:1223-1227. doi: 10.1074/jbc.R700034200 PMID: 18024427

69. Diotel N, Le Page Y, Mouriec K, Tong SK, Pellegrini E, Vaillant C, Anglade I, Brion F, Pakdel F, Chung $\mathrm{BC}, \mathrm{Kah} \mathrm{O}$. Aromatase in the brain of teleost fish: expression, regulation and putative functions. Front Neuroendocrinol. 2010; 31:172-192. doi: 10.1016/j.yfrne.2010.01.003 PMID: 20116395

70. Mouriec K, Gueguen MM, Manuel C, Percevault F, Thieulant ML, Pakdel F, Kah O. Androgens upregulate cyp 19a1b (aromatase B) gene expression in the brain of zebrafish (Danio rerio) through estrogen receptors. Biol Reprod. 2009; 80:889-896. doi: 10.1095/biolreprod.108.073643 PMID: 19129512 
71. Magee SE, Neff BD, Knapp R. Plasma levels of androgens and cortisol in relation to breeding behavior in parental male bluegill sunfish, Lepomis macrochirus. Horm Behav. 2006; 49:598-609. doi: 10.1016/j. yhbeh.2005.12.003 PMID: 16426610

72. Jones MW, Errington ML, French PJ, Fine A, Bliss TVP, Garel S, Charnay P, Bozon B, Laroche S, Davis $S$. A requirement for the immediate early gene Zif268 in the expression of LTP and long-term memories. Nature Neurosci. 2001; 4:289-296. doi: 10.1038/85138 PMID: 11224546

73. Foran CM, Bass AH. Preoptic AVT immunoreactive neurons of a teleost fish with alternative reproductive tactics. Gen Comp Endocrinol. 1998; 111:271-282. doi: 10.1006/gcen.1998.7113 PMID: 9707473

74. Ota $\mathrm{Y}$, Ando $\mathrm{H}$, Ueda $\mathrm{H}$, Urano A. Differences in seasonal expression of neurohypophysial hormone genes in ordinary and precocious male masu salmon. Gen Comp Endocrinol. 1999; 116:40-46. doi: 10. 1006/gcen.1999.7344 PMID: 10525360

75. Schlinger BA, Greco C, Bass AH. Aromatase activity in hindbrain vocal control region of a teleost fish: divergence among males with alternative reproductive tactics. P Roy Soc Lond B Biol Sci. 1999; 266:131-136.

76. Larson ET, O'Malley DM, Melloni RH. Aggression and vasotocin are associated with dominant-subordinate relationships in zebrafish. Behav Brain Res 2006; 167:94-102. doi: 10.1016/j.bbr.2005.08.020 PMID: 16213035

77. Foulkes NS, Sassone-Corsi P. More is better: activators and repressors from the same gene. Cell. 1992; 68:411-414. PMID: 1739963

78. Foulkes NS, Mellström B, Benusiglio E, Sassone-Corsi P. Developmental switch of CREM function during spermatogenesis: from antagonist to activator. Nature. 1992; 35:80-84.

79. Sassone-Corsi P. Coupling gene expression to cAMP signaling: role of CREB and CREM. Int J Biochem Cell Biol. 1998; 30:27-38. PMID: 9597751

80. Molina CA, Foulkes NS, Lalli E, Sassone-Corsi P. Inducibility and negative autoregulation of CREM: an alternative promoter directs the expression of ICER, an early response repressor. Cell. 1993; 75:875886. PMID: 8252624

81. Foulkes NS, Borjingin J, Snyder SH. Rhythmic transcription: the molecular basis of circadian melatonin synthesis. Trends Neurosci. 1997; 20:487-492. PMID: 9347618

82. Munro AD. Effects of melatonin, serotonin, and naloxone on aggression in isolated cichlid fish (Aequidens pulcher). J Pineal Res. 1986; 3:257-262. PMID: 3772724

83. Lepage O, Larson ET, Mayer I, Winberg S. Serotonin, but not melatonin, plays a role in shaping dominant-subordinate relationships and aggression in rainbow trout. Horm Behav. 2005; 48:233-242. doi: 10.1016/j.yhbeh.2005.02.012 PMID: 15896794

84. Paula JR, Messias JP, Gurtter AS, Bshary R, Soares MC. The role of serotonin in the modulation of cooperative behavior. Behav Ecol. 2015; 26:1005-1012.

85. Avila VL: A field study of nesting behavior of male bluegill sunfish (Lepomis macrochirus Rafinesque). Am Midl Nat. 1976; 96:195-206.

86. Colgan PW, Nowell WA, Gross MR, Grant JW. Aggressive habituation and rim circling in the social organization of bluegill sunfish (Lepomis macrochirus). Environ Biol Fishes. 1979; 4:29-36.

87. Gross MR. Cuckoldry in sunfishes (Lepomis: Centrarchidae). Can J Zool. 1979; 57:1507-1509.

88. Jazin E, Cahill L. Sex differences in molecular neuroscience: from fruit flies to humans. Nature Rev Neurosci. 2010; 11:9-17.

89. Parsch J, Ellegren $\mathrm{H}$. The evolutionary causes and consequences of sex-biased gene expression. Nature Rev Genet. 2013; 14:83-87. doi: 10.1038/nrg3376 PMID: 23329110

90. Asahina K, Watanabe K, Duistermars B, Hoffer E, González CR, Eyjólfsdóttir EA, Perona P, Anderson DJ. Tachykinin-expressing neurons control male-specific aggressive arousal in Drosophila. Cell. 2014; 156:221-235. doi: 10.1016/j.cell.2013.11.045 PMID: 24439378

91. Bloch GJ, Butler PC, Kohlert JG. Galanin microinjected into the medial preoptic nucleus facilitates female-and male-typical sexual behaviors in female rats. Physiol Behav. 1996; 59:1147-1154. PMID: 8737905

92. Frisch A. Sex-change and gonadal steroids in sequentially hermaphroditic teleost fish. Rev Fish Biol Fishes. 2004; 14:481-499.

93. Gao A, Wag HP, Rapp D, O'Bryant P, Wallat G, Wang W, Yao H, Tiu L, MacDonald R. Gonadal sex differentiation in the bluegill sunfish Lepomis macrochirus and its relation to fish size and age. Aquaculture. 2009; 294:138-146.

94. Arslan T, Phelps RP. Directing gonadal differentiation in bluegill, Lepomis macrochirus (Rafinesque), and black crappie, Pomoxis nigromaculatus (Lesueur) by periodic estradiol-17 $\beta$ immersions. Aquacult Res. 2004; 35:397-402. 
95. Churcher AM, Pujolar JM, Milan M, Hubbard PC, Martins RST, Saraiva JL, Huertas M, Bargelloni L, Patarnello T, Marino IAM, Zane L, Canário. Changes in gene expression profiles of the brain of male European eels (Anguilla anguilla) during sexual maturation. BMC Genomics. 2014; 15:799. doi: 10. 1186/1471-2164-15-799 PMID: 25230743 